\title{
Sustainable Return to Work: A Systematic Review Focusing on Personal and Social Factors
}

\author{
Abasiama Etuknwa ${ }^{1} \cdot$ Kevin Daniels ${ }^{1} \cdot$ Constanze Eib $^{2}$
}

Published online: 15 February 2019

(c) The Author(s) 2019

\begin{abstract}
Purpose A systematic review was conducted to evaluate the impact of important personal and social factors on sustainable return to work (RTW) after ill-health due musculoskeletal disorders (MSDs) and common mental disorders (CMDs) and to compare the effects of these personal and social factors across both conditions. Sustainable RTW is defined as a stable fulltime or part-time RTW to either original or modified job for a period of at least 3 months without relapse or sickness absence re-occurrence. Methods A literature search was conducted in 13 databases and 79 studies were selected for the review, of which the methodological design was graded as very high, high and low quality. Results The most consistent evidence for achieving sustainable RTW for both MSDs and CMDs was from support from line managers or supervisors and co-workers, positive attitude, self-efficacy, young age and higher education levels. Job crafting, economic status, length of absence and job contract/security showed promising results, but too few studies exist to draw definite conclusions. Results regarding gender were inconsistent. Conclusions This review demonstrates that a variety of personal and social factors have positive and negative influences on sustainable RTW. We suggest that the social environment and how it interrelates with personal factors like attitudes and self-efficacy should be studied in more detail in the future as the inter-relationship between these factors appears to impact positively on sustainable RTW outcomes. Areas for future research include more high-quality studies on job crafting, economic status/income, length of absence, job contract/security and gender.
\end{abstract}

Keywords Return to work $\cdot$ Musculoskeletal pain $\cdot$ Mental disorders $\cdot$ Systematic review $\cdot$ Occupational health

\section{Introduction}

Musculoskeletal and common mental disorders (MSDs and CMDs) have been recognized as the most common causes of sickness absence in developed countries, and it has become

Electronic supplementary material The online version of this article (https://doi.org/10.1007/s10926-019-09832-7) contains supplementary material, which is available to authorized users.

Abasiama Etuknwa

A.Etuknwa@uea.ac.uk

Kevin Daniels

Kevin.Daniels@uea.ac.uk

Constanze Eib

constanze.eib@psyk.uu.se

1 Norwich Business School, University of East Anglia, Norwich Research Park, Norwich NR47TJ, UK

2 Department of Psychology, Uppsala Universitet, Von Kraemers allé 1A och 1C 752 37, Box 1225, 75142 Uppsala, Sweden a major research focus, especially as the economic cost on sickness absence is growing yearly [1]. In 2014/15, approximately 1.2 million workers in Great Britain were suffering from ill-health that was either caused or worsened by their current or past jobs [2]. Of the 1.2 million workers, $80 \%$ of work-related illness was due to musculoskeletal disorders (MSDs) and common mental health disorders (CMDs) such as stress, depression or anxiety [2]. These figures constitute significant fractions of reported sickness absence episodes, and extended absence is associated with reduced probability of return to work (RTW) [3], which becomes costly for employers, increasing the urgency to help workers RTW early.

To reduce costs related to sickness absence and reduce the risk of long-term disability associated with extended absence from work, there is a big need for a better understanding of the factors that either impede or facilitate a sustainable RTW for workers sick-listed with MSDs and CMDs. Although studies have shown how work can instigate ill-health such as MSDs and CMDs [4, 5], there is 
also strong evidence that work is an important component for a speedy recovery after ill-health episodes and that work is generally beneficial for physical and mental health $[6,7]$.

Until now, systematic reviews on RTW have to a great extent focused on the effectiveness of a varied number of interventions [8-17]. However, it is still unclear what factors are effective in facilitating sustainable RTW outcomes [18, 19]. We defined sustainable RTW as a stable full-time or part-time RTW to either original or modified job for a period of at least 3 months without relapse or sickness absence reoccurrence. According to Cancelliere et al.'s [18], the process of RTW is complex and not merely dependent on the effectiveness of interventions, rather it involves an interplay of many factors beyond the health condition. Similarly, Alavi and Oxley [6] assert that when research concentrates more on learning about factors associated with sustainable RTW, further gains will be achieved in the effectiveness of RTW programmes.

Cancelliere et al. [18] conducted a systematic review of reviews to identify prognostic factors for RTW and their association with RTW outcomes. Cancelliere et al.'s study [18] identified higher education levels, higher socio-economic status, higher self-efficacy and optimistic expectations for recovery and RTW, lower severity of injury/illness, better RTW coordination and multidisciplinary interventions as common prognostic factors associated with a positive RTW. Cancelliere et al.'s [18] findings introduced a promising line of direction; that employee's personal and social relations in the workplace both play an important role for better understanding RTW. However, sustainable RTW was not the outcome measure in that review, and ill-health was not limited to MSDs and CMDs but extended across different health and injury conditions. Thus, there warrants a review specifically addressing sustainable RTW outcomes for people with MSDs and CMDs. Similarly, Gallagher et al. [20] suggested that lasting RTW outcomes may be achieved through employees' personal factors like age and length of sickness absence and psychosocial factors like social support, health locus of control and illness behaviour. In recent times, there has been similar suggestions to improve RTW models and policies to take into account these personal and social factors in the workplace [21-24]. However, there are currently no reviews explicitly investigating the effects of personal and social factors on sustainable RTW outcomes for MSDs and CMDs, as such, a review like our current review could help uncover the factors that can account for the stability of absence due to MSDs and CMDs in advanced economies, in spite of evidence for the effectiveness of RTW interventions [8-11]. Additionally, in the current literature on RTW, there is a heavy focus on MSDs, especially low back pain and little on CMDs [18]. This review seeks to address these gaps in evidence, thus providing a unique contribution to the literature on sustainable RTW after illhealth due to MSDs and CMDs.

Very few guidelines on sickness absence management address both MSDs and CMDs holistically, although there are striking parallels between both conditions [25]. Both conditions share similarities in health characteristics relating to delayed onset, delayed recovery, reduced life expectancy and unclear diagnosis which in many cases may result in chronic absences [26, 27]. The RTW processes and psychosocial risk factors for these conditions are also similar [26, 27]. According to Heuvel [28], even though psychosocial risk factors are often associated with CMDs, several studies have demonstrated that they also have an effect on MSDs. The association between MSDs and CMDs has been widely investigated, and findings indicate that people of working age with CMDs are often coexisting with MSDs which may influence a person's successful RTW [29]. Therefore, there are several reasons to investigate RTW outcomes for both MSDs and CMDs together.

This review focused on identifying various employee's personal and social factors taken into account in both intervention and non-intervention-based studies reporting sustainable RTW outcomes for people sick-listed with MSDs and CMDs. Sustainable RTW is difficult to define especially as different studies use varying durations for outcome measures because of the difference in absence duration for MSDs and CMDs [30]. According to Krause et al. [31], because measures of duration of disability and RTW outcomes serve multiple functions in principle, it becomes important to clearly state the function of outcome measures. As such the function of sustainable RTW outcome in this review was to identify a stable period of return after sick-leave without a relapse. Jensen et al. [32] defined sustainable RTW for people sick-listed with MSDs as the first period of four consecutive weeks without receiving healthrelated benefits. They argued that the 4-week period without relapse was considered sufficiently long enough to suggest a lasting and stable return. Conversely, Lammerts et al.'s [10] study on sick-listed workers with a depressive or anxiety disorder operationalized sustainable RTW as employed participants who have not been long-term sick-listed (more than 14 days) in the previous 6 months. Hoefsmit et al. [22] investigated RTW outcomes for employees sick-listed with all ill-health apart from terminally ill employees, and defined sustainable RTW as working for four weeks without relapse in partial or complete sick-leave. In this review, sustainable RTW was formulated with a timeframe of at-least 3 months without relapse or absence. Across the included studies in this review, 3 months was the lowest follow-up period of which successful return to full-time and part-time work was recorded for people sick-listed with both MSDs and CMDs. Like Jensen et al. [32], we argue that RTW for at-least 3 months with no recorded incidence of relapse and 
subsequent absence is considered a sufficiently long enough timeframe to suggest sustainability of return for people with both conditions. The 3 months' timeframe also takes into account the different recovery and RTW period for both MSDs and CMDs identified in previous studies.

The aim of this systematic review was to assess the impact of personal and social factors on a sustainable RTW after ill-health due to MSDs or CMDs. In addition, we aimed to identify commonalities of effects of these personal and social factors between both conditions. Personal factors identified included attitude, self-efficacy, age, gender, education, economic status/income, length of sickness absence, job contract/ security. Social factors identified included support from leaders and co-workers (where leaders include managers, line managers, supervisors etc.) and job crafting and its related practices (employee-initiated changes to job or how work is done). Job crafting refers to employees redesigning their job task to fit their motives, strengths and passions $[33,34]$. This concept of job redesign helps to capture the actions employees independently take to shape, mould and redesign their jobs [35]. According to Wrzesniewski and Dutton [35], by crafting one's job, individuals are accorded the opportunity to change not just the elements of their jobs, but also their relationship with others to redefine the meaning of their work and the social environment of their work.

Findings from this review will help us understand what factors may either instigate or hinder a sustainable RTW. The review intends to provide employers and policy makers with knowledge of key factors that will aid in implementing more effective RTW programmes. It will also add to the body of evidence on the impact of personal and social factors on RTW outcomes which is currently limited [16], inform policy decision making and provide avenues for future research in the field of RTW.

\section{Methods}

The systematic review was conducted in line with the Preferred Reporting Items for Systematic Reviews and MetaAnalyses (PRISMA) guidelines [36]. The protocol was duly developed prior to the review and registered with PROSPERO (https://www.crd.york.ac.uk/PROSPERO/displ ay_record.asp?ID=CRD42016053967) (registration no; CRD42016053967).

\section{Literature Search}

A systematic review of sustainable RTW after ill health was conducted. A search strategy based on PICOS strategy was formulated [37]. This strategy allows its five components (population, intervention, comparator, outcome and study design) to be taken into account when developing a search strategy that is unbiased, reproducible and helps to rapidly and accurately locate the best available and relevant scientific literature that fit into the scope of the review and answer the research questions [38].

However, because this review had no specific comparator, the research question was derived in terms of the participant, intervention, outcome related to the risk posed and study design suitable for addressing it (PIOS) [37, 39].The search inclusion criteria included studies that reported on employees returning to work after absence due to MSDs or CMDs (population), the effects of personal and social factors on RTW outcomes (intervention), a sustained RTW after illhealth such as MSDs or CMDs (outcome) and studies of all designs published in English from 1989 to 2017. Out of a need to accurately assess RTW approaches and interventions that have taken into account personal and social factors, the timeframe was extended to include 1989. Even though research as far back as 1989 may not necessarily provide evidence generalizable in today's work environment, it was considered relevant to include this research because this range included an early, if not the earliest paper that explored the association between multiple personal and social factors and successful RTW [20]. Based on this, search terms were developed, and the first author conducted a comprehensive search of relevant electronic databases including published and unpublished research, grey literature and reference lists of both primary studies and reviews. Table 1 shows the search terms that the first author adopted during the search. The search was conducted between October 2016 and March 2017 on 13 databases: Business Source Complete, CINAHL, Cochrane Library, EBOSCO Host, JSTOR, Medline (OVID), Psych INFO, PubMed, Scopus, ScienceDirect, SPORT Discus, Web of Science and Wiley Online Library (see Online Resource 1 for a summary of the search result for each database).

\section{Selection of Studies}

The first author conducted the selection of relevant studies in three stages: (i) Title; (ii) Abstract; and (iii) Full-Text/ Paper screening. A title screening was conducted to retrieve papers specifically reporting RTW outcomes for CMDs and MSDs. At this stage, if the study indicated the RTW outcome for ill-health other than MSDs and CMDs, the article was excluded. Identified citations were further sifted according to the abstract, to select citations eligible for possible inclusion in the review.

In the third stage, the first author assessed the full-text/ paper for quality and relevance to the research question. Where a study did not meet the inclusion criteria, the paper was excluded. All retrieved studies were screened independently by the first author and $30 \%$ each further checked by the other authors to ensure reliability and transparency in the 
Table 1 Search terms used

\begin{tabular}{|c|c|c|c|c|}
\hline & Population & Intervention & Outcome & Study design \\
\hline \multirow[t]{26}{*}{ Possible search terms } & $\begin{array}{l}\text { - Return* to work } \\
\text { employee* }\end{array}$ & - Leader* & - Sustain* return* to work & - Randomi*controlled trial* \\
\hline & - Return* to work officer* & - Co-workers & - Bearable return* to work & - Intervention* \\
\hline & - Return* to work worker* & - Social support & - Endurable return* to work & - Cohort \\
\hline & - RTW rehab* & - Employee* character & - Sustain* recovery & - Experimental \\
\hline & - Occ* rehab* & - Job crafting & - Back to work & - Randomi* \\
\hline & • Employee* & - Managers & - Sustain* back to work & - Trial* \\
\hline & - Absent from work & - Supervisors & - Bearable back to work & $\begin{array}{l}\text { - 'Clinical Trial' [publication } \\
\text { type] }\end{array}$ \\
\hline & $\begin{array}{l}\text { - Worker* absence from } \\
\text { work }\end{array}$ & - Colleagues & - Endurable back to work & $\begin{array}{l}\text { - "Meta-analysis" [publication } \\
\text { type] }\end{array}$ \\
\hline & - Return* to work staff & - Job re-design & - Workability & - Quasi-experiment \\
\hline & $\begin{array}{l}\text { - Employee* returning from } \\
\text { ill-health }\end{array}$ & - Job altering & & - Systematic review \\
\hline & $\begin{array}{l}\text { - Worker* returning from } \\
\text { ill-health }\end{array}$ & - Organi* changes & & - Evidence synthesis \\
\hline & $\begin{array}{l}\text { - Staff returning from ill- } \\
\text { health }\end{array}$ & - Personal trait & & - Observational \\
\hline & - Employee* with MSDs & - Individual difference & & - Qualitative \\
\hline & - Worker* with MSD & - Supervision & & - Survey \\
\hline & - Staff with MSDs & - Adaptation* & & - Mixed \\
\hline & $\begin{array}{l}\text { - Employee* with depres- } \\
\text { sion }\end{array}$ & - Interventions & & - Quantitative \\
\hline & - Worker* with depression & - Job modification & & \\
\hline & - Staff with depression & - Climate & & \\
\hline & - Sickness presence & - Vocational & & \\
\hline & - MSDs & - Rehab* & & \\
\hline & - Musculoskeletal disorders & - Supported employment & & \\
\hline & - Depression & - Work adjustment & & \\
\hline & - Mental health issues & - Occupation* adjustment & & \\
\hline & • Ill-health & - Workplace intervention & & \\
\hline & - Time loss from work & - Modified work & & \\
\hline & & - Occupational intervention & & \\
\hline
\end{tabular}

selection process, consistency in interpretation and eligibility of included studies in the final review.

\section{Quality Appraisal}

Methodological quality of individual studies was assessed using the Critical Appraisal Skill Programme (CASP) Checklist for qualitative and mixed studies and the checklist of evidence quality adapted from the "Early Intervention Foundation" (EIF) for quantitative studies adapted from Snape et al. [40]. Each aspect of the study was given a quality rating ('yes', 'no' or 'can't tell)' based on the criteria on the checklist [40] (see Online Resources 8 and 9 for assessment tools). Based on the checklist criteria, studies were considered of good methodological quality and therefore included in the review if the answers to all the screening question were 'yes'. However, a concession was agreed also include studies that recorded a few 'no' or 'can't tell' answers based the degree to which an evaluated factor has been shown to have a positive impact on specific outcomes (EIF) and on the relevance of findings, appropriate methodology and rigor in analysis (CASP). As a result, all studies were included in the summary regardless of the methodological quality. The first author independently assessed the methodological quality of each study using both assessment tools, of which the other authors checked for consistency to address inter-rater reliability.

The final quality grading for the quantitative studies was based on the grading recommendations assessment development and evaluation (GRADE) approach [41], the qualitative and mixed studies were based on the confidence of evidence from reviews of qualitative research (CERqual) [42]. 
In GRADE, multiple randomized controlled trials (RCTs) with good statistical power converging on reliable effect sizes with narrow intervals are considered as 'high-quality' evidence. Well-designed observational studies with good statistical power are considered as 'low-quality' evidence. However, GRADE allows flexibility in rating evidence at a higher or lower level depending on a range of considerations. For example, evidence initially rated as 'high-quality' can be downgraded due to study limitations, inconsistency of results, indirectness of evidence, imprecision and reporting bias. Similarly, evidence initially rated a 'low-quality' can be upgraded to high-quality if there is a very large magnitude of effect, a dose-response gradient, and all plausible biases would reduce an apparent treatment effect [40]. In this review RCTs were categorized as very high-quality and upgraded observational studies were categorized as highquality to aid clear distinction between both study designs. CERqual approach uses a similar approach to the GRADE tool to grade the quality of evidence [40]. Qualitative and mixed studies were thus graded very high-quality based on four components. The methodological limitations of the studies contributing to a review finding, relevance to the review question of the studies contributing to a review finding, coherence of the review finding, and adequacy of data supporting a review finding.

Therefore, both GRADE and CERqual approaches were used to inform a final assessment of the quality of the findings of the review, as such, data extraction and evidence synthesis were completed on very-high, high and low-quality studies.

\section{Data Extraction}

A data extraction form was designed using the PIOS (Population, Intervention, Outcome and Study Design) strategy to minimize the possible errors or biases that may occur at this stage [37]. This data extraction form was designed based on how the research question was formulated with a view to obtaining all the relevant information from included studies [43]. This strategy was helpful in gaining a deeper understanding of the evidence to prevent error in interpretation as well as enhanced transparency of the method of analysis [43]. Data extraction sheets were thus designed to capture all the necessary study details e.g. author, study design and more detailed information about the nature of the intervention, personal and social factors and the outcomes. To ensure consistent extraction of necessary information from the studies, the authors conducted a pilot exercise. Data were extracted from ten random papers by all of the authors, who then discussed any discrepancies or differences in interpretation of the papers to ensure consistent data extraction from all of the included articles. Following the pilot exercise, the data extraction sheet was augmented to require more information on papers to aid easy understanding and prevent returning to the original paper for clarification (see Online Resource 2 for the full data extraction sheet).

\section{Evidence Synthesis}

Once data were extracted, the first author synthesized the data extraction sheets into an evidence summary table (See Online Resource 3). Since the outcome measures of included studies were very heterogeneous, data was synthesized using narrative synthesis. Hence a series of harvest plots (adapted from [44]) (see Online Resources 4, 5, 6, 7) and evidence statements summarizing the quality of evidence (see Table 2) were developed by the first author based on two distinct categories of ill-health (MSDs and CMDs). These plots are an effective means in visualizing findings in a way that takes the quality of study into account [45]. Each plot consists of three columns representing the three-competing hypotheses (positive effect, negative effect and no effect) and a bar represents each study in each of the columns according to the competing hypothesis results of the study supported. The row represents the domains of the evaluated personal and social factors (support from leaders, support from coworkers, job-crafting and personal characteristics). Based on the included studies, personal characteristics included positive attitude to work and the return to work process, high self-efficacy, younger age, gender, high education, low economic status/income, short-term length of absence and temporary or insecure job contract. The quality of evidence in the review is indicated by the height of the bar with a specific designation on it in each row ( $\mathrm{H}$ to represent very highquality studies, $\mathrm{U}$ to represent low-quality studies upgraded to high quality based on the GRADE criteria and L to represent low-quality studies, see below). Studies with relatively stronger designs (RCT) are indicated with full-tone (black) bars, and weaker study designs (observational and qualitative/mixed studies) are marked with half tone (grey) bars.

Evidence showing common factors was organized using the International Classification of Functioning, Disability and Health (ICF) framework which is useful for assessing, describing and organizing information on health status and disability across different cultures and settings [46]. This framework was chosen because it has previously been used to evaluate RTW factors across different health conditions [18]. The ICF is composed of four broad components: personal (e.g. age, sex), the body functions and structures (e.g. disease injury-related), activity limitation (e.g. history of sickness absence, inability to perform some activities of daily living), and environmental factors (e.g. all factors related to working conditions, work environment, work support and accommodation). However, only personal and environmental factors of the ICF framework was taken into account in this review as evaluated factors did not extend to 


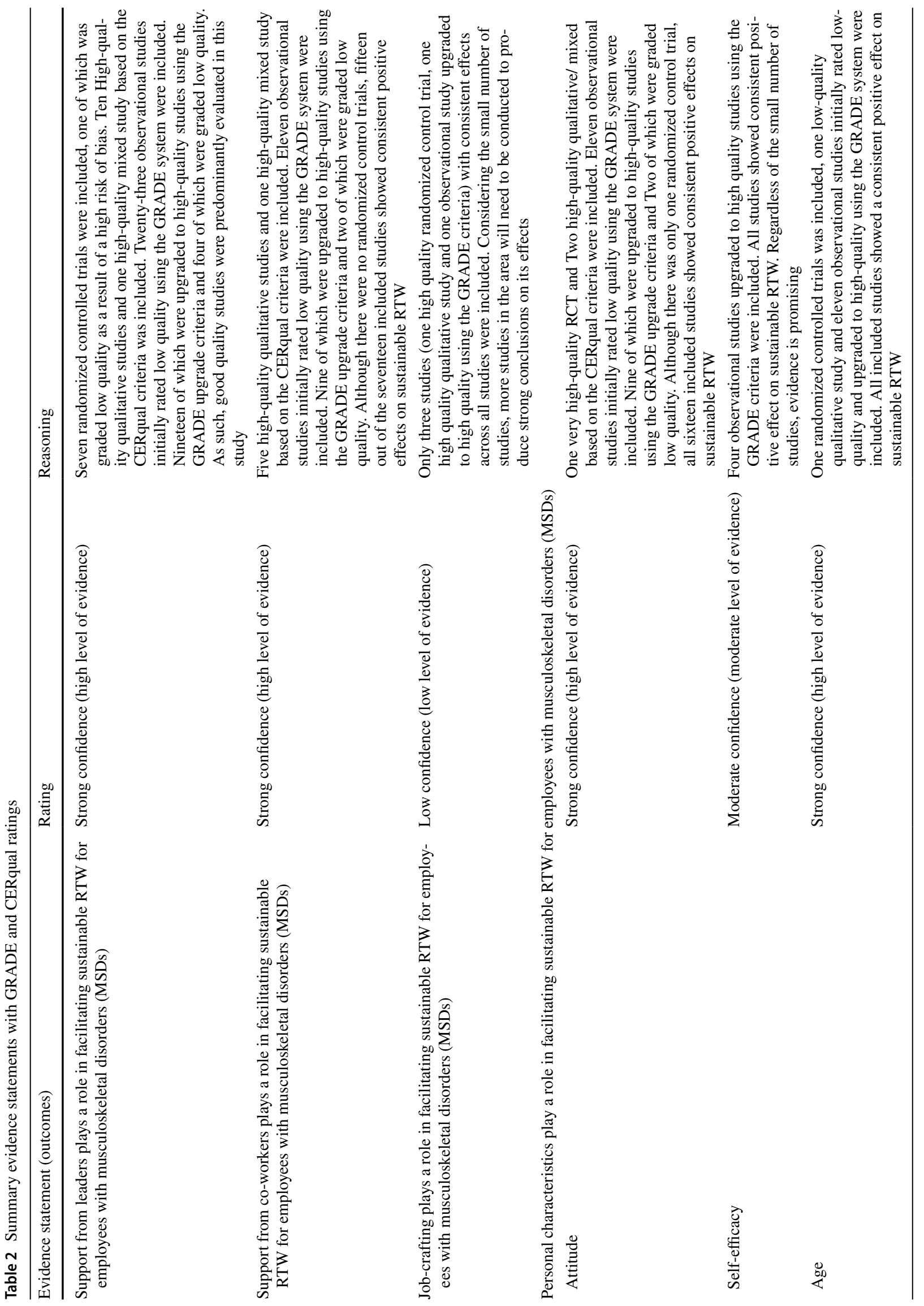




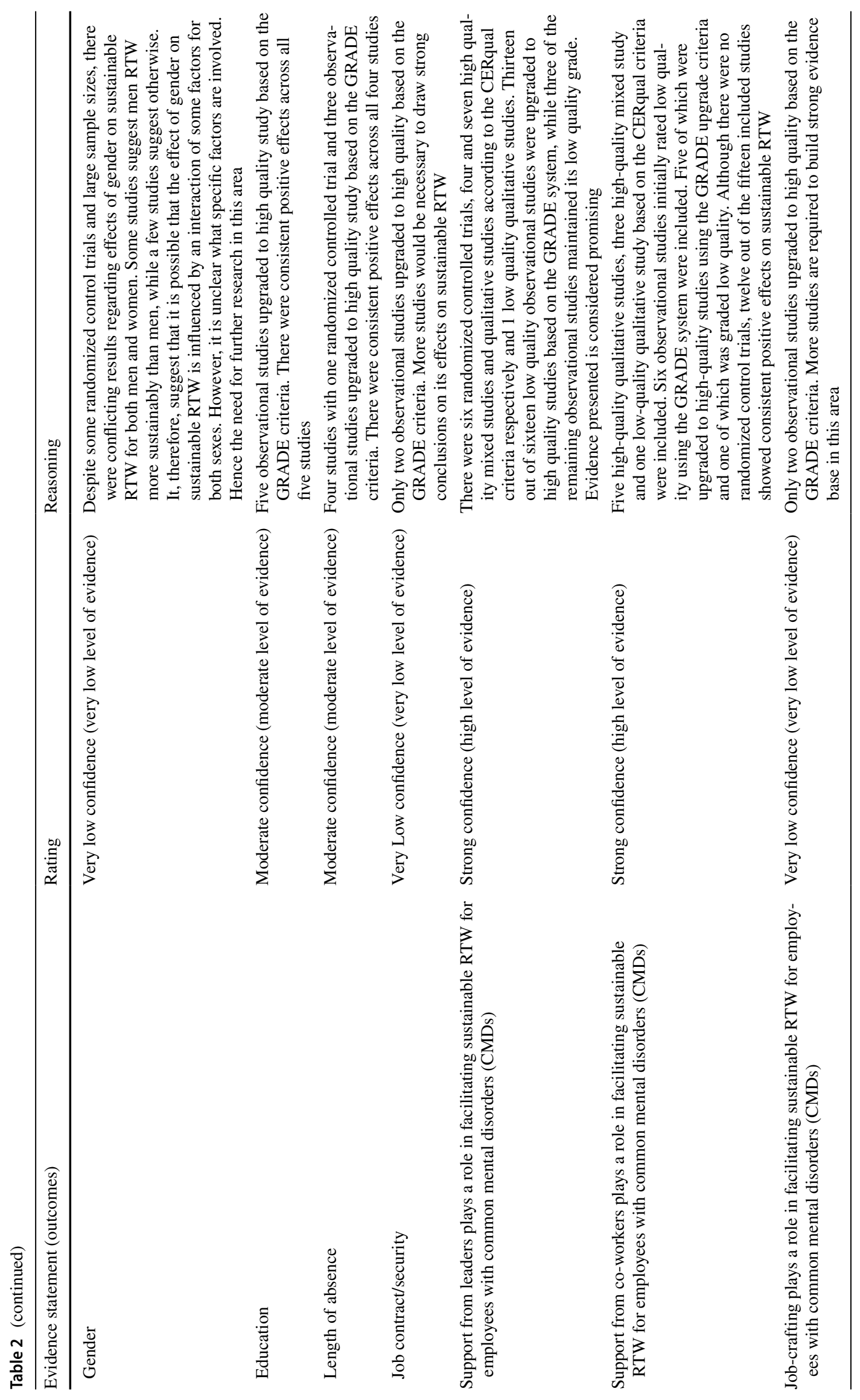




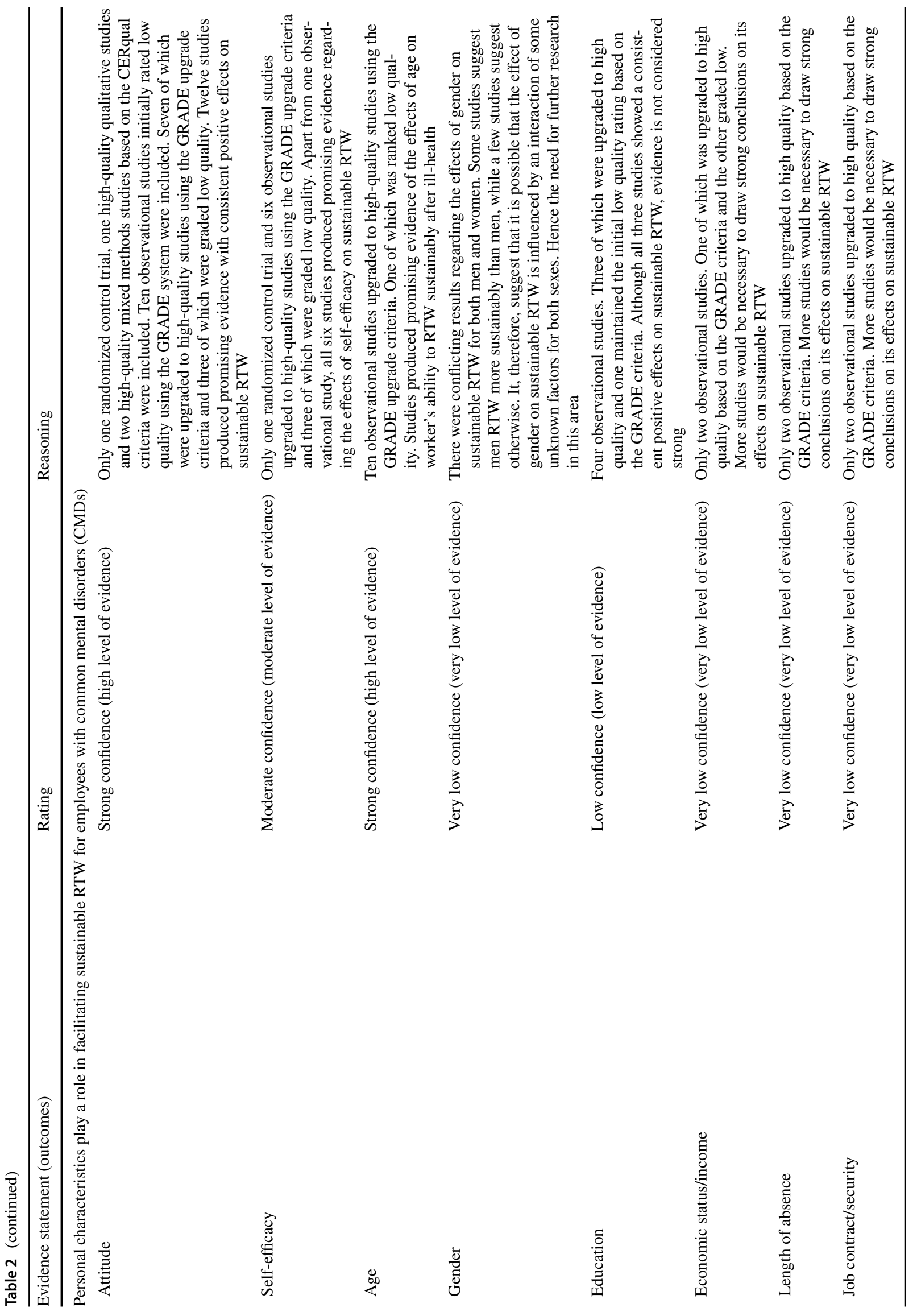




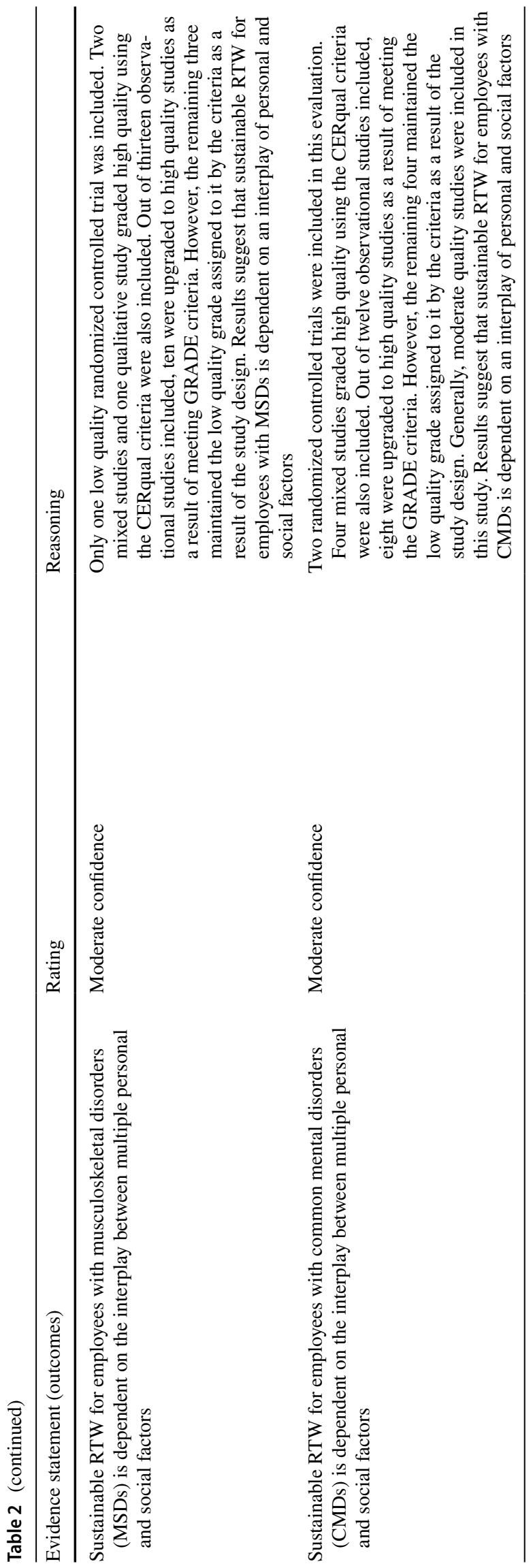

other components, apart from personal and social factors which are classed under each component respectively.

The level of confidence in the overall body of evidence for each personal and social factor in this review was rated in four categories of evidence (strong, moderate, low and very low confidence) developed from the GRADE and CERqual approach [47]. Where there is confidence that a factor impacted on sustainable RTW outcomes, evidence was rated 'strong confidence' (high level of evidence). 'Moderate confidence' (moderate level of evidence) suggests that an impact may occur but requires further investigation. Level of evidence was rated 'low confidence' (low level of evidence) where further research is required and although an effect may occur, there is less confidence than for evidence of 'moderate confidence'. Where there was insufficient evidence to draw conclusions, evidence was rated 'very low confidence' (very low level of evidence). Confidence in the evidence was decided by discussion and consensus by the review authors, by balancing the number of studies showing an effect in a consistent direction and the quality of those studies as indicated in the sections below.

However, in practice, evidence was rated strong where at least 10 studies showed positive effects and no more than three studies showed null effects or where 28 or more studies showed positive effects, no more than five showed null effects and only 1 showed negative effects. Evidence was rated a moderate/low where at least four/three studies showed a positive effect and there were no studies showing null or negative effects. Where there were only two studies showing an effect, even if the effect was consistent, we deemed this a low level of evidence. Evidence was also rated as very low where there were inconsistent or contradictory results, which was where there were no more than four studies showing an effect in one direction and at least one study showing an effect in the other direction.

\section{Results}

\section{Literature Search}

Our search strategy identified 40,276 citations related to the research topic on the thirteen databases, online trial registers, grey literature, and reference lists. After duplicate entries, non-peer reviewed published work and studies of foreign languages were eliminated from combined citations from all the databases, 4385 citations were potentially eligible for inclusion in the review.

\section{Selection of Studies}

After removing 4161 citations at the title screening stage, 224 citations were left for the abstract screening. Of the 224 
citations screened at this stage, 127 were left for the full-text screening stage. Out of 127 full-text articles retrieved, there was a unanimous agreement among the authors to include 58 papers and exclude 33 papers. However, there were disagreements between the authors on the eligibility of 36 studies evaluating the effectiveness of interventions on RTW outcomes. After further review of each of the 36 papers and in-depth discussions on its relevance or irrelevance, the authors finally agreed to include 21 citations (studies that took into account the impact of personal and/or social factors) and excluded 15 citations (studies with no personal and/or social factors in evaluation). Overall, of the 127 fulltexted citations, a total of 48 papers were excluded based on not meeting the inclusion criteria. Seventy-nine articles were included in the final analysis. 55 studies of which reported RTW outcomes for workers sick-listed with MSD, while 45 studies reported RTW outcomes for workers sick-listed with CMDs. A flow chart (see Fig. 1) was developed to show the transparency of the selection process.

\section{Quality Appraisal}

Out of the 18 randomized controlled trials that started out as very high-quality studies, one study was downgraded to low-quality as it did not take account of all confounding factors. Out of the 45 observational studies that started out as low-quality studies based on the standard GRADE rating, 42 were upgraded to high-quality studies as they met all the GRADE upgrade requirements. Based on the CERqual rating, out of the 16 qualitative and mixed studies included, one qualitative study was categorized as low-quality as a result of a lack of rigor in analysis and relationship between participants and researcher was not adequately considered [40]. The remaining 15 studies were categorized as high-quality because they fulfilled all the assessment criteria [40]. Taken as a whole, the quality of included articles reporting RTW outcomes for MSDs and CMDs did not affect the findings. Table 2 summarizes the main findings and the quality of the evidence supporting the main findings.

\section{Data Extraction}

\section{Study Characteristics}

A total of 55 studies assessed the effects of personal and social factors on sustainable RTW due to MSDs. The study designs included randomized controlled trials (RCTs) $(\mathrm{N}=12)$, observational studies $(\mathrm{N}=33)$, qualitative studies $(\mathrm{N}=9)$ and mixed methods studies $(\mathrm{n}=1)$. Studies that examined whether there is evidence supporting suggestions
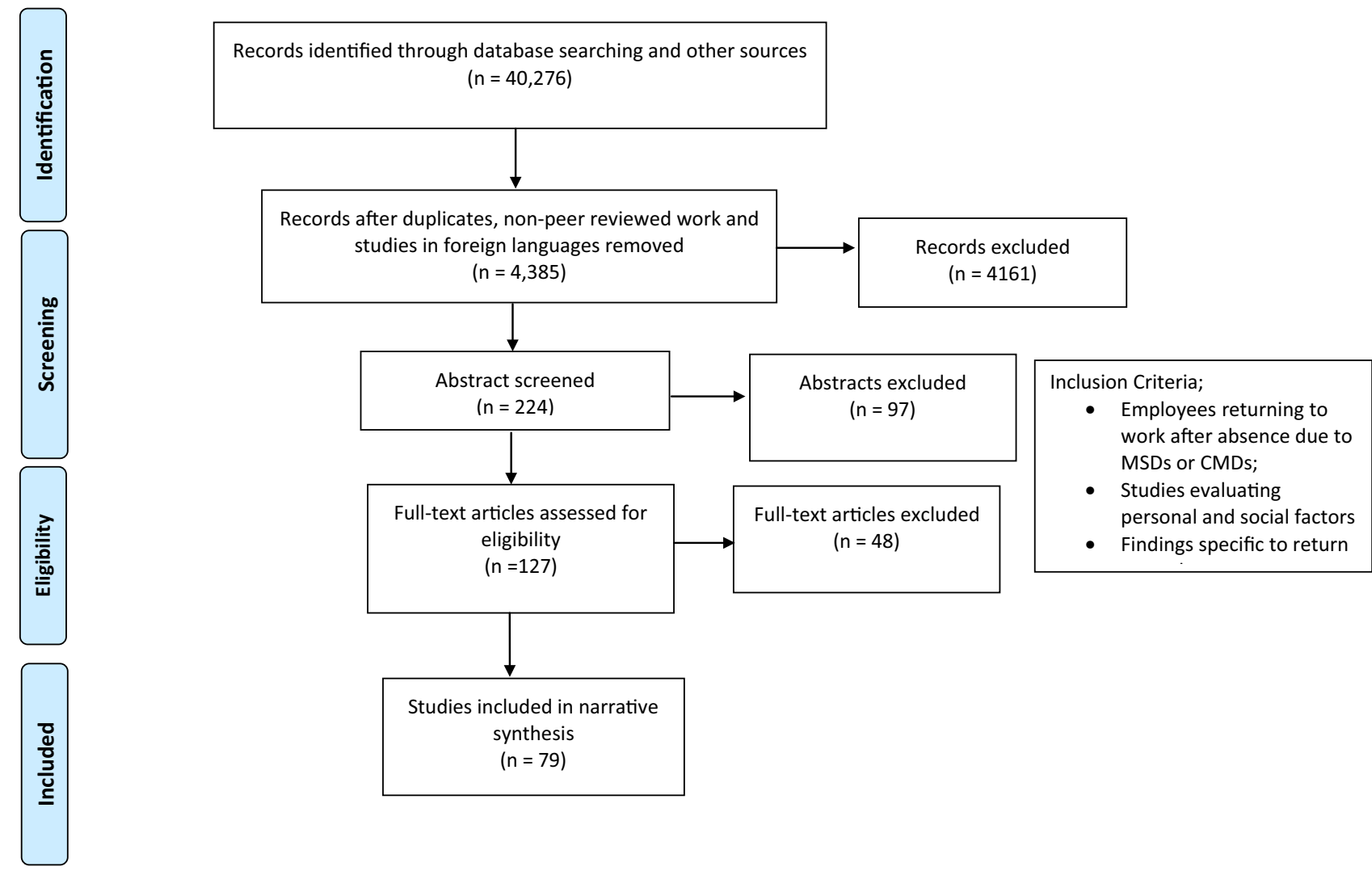

Fig. 1 Flow chart of studies eligible for inclusion (Reproduced with permission from Moher et al. [71]) 
that personal and social factors impact sustainable return to work (RTW) after ill-health due to CMDs totalled 45. The study designs included RCTs $(\mathrm{N}=6)$, observational studies $(\mathrm{N}=27)$, qualitative studies $(\mathrm{N}=8)$ and mixed studies $(\mathrm{N}=4)$. Workers in various occupational sectors returning to work after absence of at least two weeks due to MSDs and/ or CMDs were represented in this review. Average age of study population ranged from 16 to 65 years. The majority of the studies (60 of 79) were conducted in Europe (Austria, Denmark, Finland, Ireland, Norway, Netherlands, Sweden, and United Kingdom). Five studies were undertaken in the United States, thirteen in Canada, and one each in Australia and China. Personal factors identified and evaluated included employee's personal characteristics such as: attitude, selfefficacy, age, gender, education, economic status/income, length of sickness absence and job contract/security. Social factors identified and evaluated included support from leaders and co-workers and job-crafting practices.

\section{Evidence Synthesis}

We reported findings from this review in two main categories; first, evidence on the effects of personal and social factors on sustainable RTW after ill-health due to MSDs or CMDs and second, evidence on personal and social factors common to both MSDs and CMDs. Personal and social factors that were common across MSDs and CMDs were determined based on the conclusions drawn from the evidence synthesis for both conditions. Outcomes were described in five groups (positive, negative, inconsistent, inconclusive and no effect). Common personal and social factors across MSDs and CMDs were deduced from consistent evidence from more than one study for both conditions. Where the majority of the outcomes $(50 \%$ or more of the studies reporting a positive RTW outcome) in the review for each factor was in the same direction, evidence was considered consistent (see Table 3). Numerical representation of individual studies shown in the results is reported based on the evidence summary table presented in Online Resource 3.

\section{Evidence on the Effects of Personal and Social Factors on Sustainable RTW After III-Health}

Included studies presented a varied level of evidence ranging from strong to very low on the effects of personal and social factors on sustainable RTW for MSDs and CMDs.

\section{Attitude}

MSDs Three very high-quality studies $(18,34,58)$, nine high-quality studies $(8,10,11,16,20,32,44,61,78)$ and four low-quality studies $(3,23,24,46)$ provided a strong level of evidence supporting the helpful effects of a positive attitude towards work and the RTW on sustainable RTW.

CMDs While one very high-quality study (18) and one high quality study (11) did not find any association between attitude and sustainable RTW, three very high-quality studies (34, 53, 74), six high-quality studies $(10,16,32,55,77$, $78)$ and three low-quality studies $(22,23,24)$ provided a strong of evidence that people with a positive attitude are more likely to RTW sustainably than those with a negative attitude towards work and the RTW process.

\section{Self-Efficacy}

MSDs In four high-quality studies (10, 11, 16, 36), sustainable RTW was associated with self-efficacy, providing moderate level of evidence that employees with a high sense of self-efficacy are likely to RTW sustainably than those with a low self-efficacy.

CMDs One very high-quality study (72) and seven highquality studies $(10,11,16,36,45,77)$ examined the effects of self-efficacy. Apart from one study (36), all studies provided moderate evidence suggesting that employees with a high-self-efficacy during the RTW process have a greater likelihood of returning to work sustainably than those with a low sense of self-efficacy.

\section{Age}

MSDs One very high-quality study (68), one low-quality study (46) and eleven high-quality studies (15, 16, 28, 32, $33,36,48,50,61,69,78)$ provided a consistent positive effect of age on ability to RTW sustainably, providing a strong level of evidence showing that younger employees of age ranged between 16 and 45 years have a higher probability of remaining at work after return than the older employees.

CMDs Across all nine high-quality studies (16, 25, 32, 33, $36,47,69,77,78)$ and one low-quality study (62), there is a strong level of evidence that being of a younger age (1645 years) increases the likelihood of returning to work faster and sustainably compared to being of an older age which contributes to delay in recovery and lasting RTW.

\section{Gender}

MSDs Two high-quality studies $(15,48)$ reported sustainable RTW in women, while one very high-quality study (58) and three high-quality studies $(17,48,50)$ reported sustainable RTW in men. Based on these inconsistencies in the findings, it is unclear which gender of the two is more likely to 
Table 3 Common personal and social factors
Author

Condition

Sustainable RTW outcome

\begin{tabular}{|c|c|c|}
\hline \multicolumn{3}{|l|}{ Positive outcomes } \\
\hline \multicolumn{3}{|l|}{ Personal factors } \\
\hline \multicolumn{3}{|l|}{ Positive attitude } \\
\hline Anema 2003 & MSDs & + \\
\hline Bensen 2015 & MSDs & + \\
\hline Brouwer 2009 & MSDs + CMDs & + \\
\hline Brouwer 2010 & MSDs & + \\
\hline D'Amato 2010 & MSDs + CMDs & + \\
\hline Dionne 2013 & MSDs & + \\
\hline Dunstan 2013 & MSDs & + \\
\hline Ekbladh 2010 & MSDs + CMDs & + \\
\hline Ekbladh 2004 & MSDs + CMDs & + \\
\hline Heijbel 2006 & MSDs + CMDs & + \\
\hline Hoefsmit 2014 & MSDs + CMDs & + \\
\hline Labriola 2006 & MSDs & + \\
\hline Laisne 2013 & MSDs & + \\
\hline Opsahl 2016 & MSDs & + \\
\hline Reiso 2003 & MSDs & + \\
\hline Wahlin 2012 & MSDs + CMDs & + \\
\hline Ekberg 2015 & CMDs & + \\
\hline Martin 2015 & CMDs & + \\
\hline Nielsen 2013 & CMDs & + \\
\hline Van Oostrom 2009 & CMDs & + \\
\hline Volker 2015 & CMDs & + \\
\hline \multicolumn{3}{|l|}{ Self-efficacy } \\
\hline Brouwer 2009 & MSDs + CMDs & + \\
\hline Brouwer 2010 & MSDs + CMDs & + \\
\hline D'Amato 2010 & MSDs + CMDs & + \\
\hline Huijs 2012 & MSDs & + \\
\hline Lagerveld 2010 & CMDs & + \\
\hline Van Beurden 2015 & CMDs & + \\
\hline Volker 2015 & CMDs & + \\
\hline \multicolumn{3}{|l|}{ Younger age } \\
\hline Crook 1994 & MSDs & + \\
\hline D'Amato 2010 & MSDs + CMDs & + \\
\hline Gallagher 1989 & MSDs & + \\
\hline Heijbel 2006 & MSDs + CMDs & + \\
\hline Heijbel 2013 & MSDs + CMDs & + \\
\hline Huijs 2012 & MSDs + CMDs & + \\
\hline Laisne 2013 & MSDs & + \\
\hline Lederer 2012 & MSDs & + \\
\hline Lydell 2009 & MSDs & + \\
\hline Reiso 2003 & MSDs & + \\
\hline Steenstra 2009 & MSDs & + \\
\hline Stoltenberg 2010 & MSDs + CMDs & + \\
\hline Wahlin 2012 & MSDs + CMDs & + \\
\hline Engstrom 2007 & MSDs & + \\
\hline Lammerts 2016 & CMDs & + \\
\hline Roelen 2012 & CMDs & + \\
\hline
\end{tabular}


Table 3 (continued)

\begin{tabular}{llr}
\hline Author & Condition & $\begin{array}{c}\text { S } \\
\text { a } \\
\text { Volker 2015 }\end{array}$ \\
Higher education & CMDs & + \\
D'Amato 2010 & & + \\
Huijs 2012 & MSDs +CMDs \\
Lydell 2009 & MSDs & + \\
Muijzer 2011 & MSDs & + \\
Wahlin 2012 & MSDs +CMDs & + \\
Ekberg 2015 & MSDs +CMDs & + \\
\end{tabular}

Sustainable RTW outcome

Inconsistent outcomes

Gender

De Rijk 2008

Lederer 2012

Lydell 2009

Opsahl 2016

Crook 1994

Johansson 2006

Roelen 2012

Volker 2015

Laisne 2013

No effects

Positive attitude

Brouwer 2010

MSDs + CMDs

$+/-$

MSDs

$+/-$

MSDs

$+/-$

MSDs

$+/-$

MSDs

$+/-$

CMDs

$+/-$

CMDs

$+/-$

CMDS

$+1-$

MSDs

$+/-$

De Vries 2014

CMDs

None

Self-efficacy

Huijs 2012

CMDs

None

Inconclusive outcomes

CMDs

None

Low economic status/income

Lammerts 2016

CMDs

$+/ ?$

Roelen 2012

CMDs

$+/ ?$

Short-term length of absence

Gallagher 1989

MSDs

$+/ ?$

Heijbel 2006

Lydell 2009

Steenstra 2009

MSDs + CMDs

$+/ ?$

MSDs

$+/ ?$

MSDs

$+/ ?$

Engstrom 2007

CMDs

$+/ ?$

Temporary and insecure job contract

MSDs + CMDs

$+/ ?$

Huijs 2012

Lederer 2012

Lammerts 2016

MSDs

$+/$ ?

CMDs

$+/ ?$

Positive outcomes

Environmental factors: social factors

Support from leaders

Ahltrom 2013

Anema 2003

Baril 2003

Bernacki 2000

Brouwer 2009

Brouwer 2010

Brouwer 2011

MSDs + CMDs
MSDs
MSDs
MSDs + CMDs
MSDs + CMDs
MSDs
MSDs

+
+
+
+
+
+
+


Table 3 (continued)

\begin{tabular}{|c|c|c|}
\hline Author & Condition & $\begin{array}{l}\text { Sustain- } \\
\text { able RTW } \\
\text { outcome }\end{array}$ \\
\hline Bultmann 2009 & MSDs & + \\
\hline Burtler 2007 & MSDs & + \\
\hline D'Amato 2010 & MSDs + CMDs & + \\
\hline Dionne 2013 & MSDs & + \\
\hline Durand 2000 & MSDs & + \\
\hline Ekbladh 2004 & MSDs + CMDs & + \\
\hline Franche 2007 & MSDs & + \\
\hline Friesen 2001 & MSDs + CMDs & + \\
\hline Haugli 2011 & MSDs + CMDs & + \\
\hline Haveraaen 2016 & MSDs & + \\
\hline Heijbel 2013 & MSDs + CMDs & + \\
\hline Hoefsmit 2014 & MSDs + CMDs & + \\
\hline Hu 2014 & MSDs & + \\
\hline Janssen 2003 & MSDs + CMDs & + \\
\hline Jakobsen 2014 & MSDs & + \\
\hline Jensen 2012 & MSDs & + \\
\hline Labriola 2006 & MSDs & + \\
\hline Laisne 2013 & MSDs & + \\
\hline Loisel 1997 & MSDs & + \\
\hline Lysaght 2008 & MSDs + CMDs & + \\
\hline Muijzer 2011 & MSDs + CMDs & + \\
\hline Selander 2015 & MSDs + CMDs & + \\
\hline Shaw 2008 & MSDs & + \\
\hline Shiri 2011 & MSDs & + \\
\hline Steenstra 2006 & MSDs & + \\
\hline Tjulin 2011 & MSDs + CMDs & + \\
\hline Vermeulen 2011 & MSDs & + \\
\hline Wainwright 2013 & MSDs & + \\
\hline Andersen 2014 & CMDs & + \\
\hline Arends 2013 & CMDs & + \\
\hline Bond 2001 & CMDs & + \\
\hline De Vries 2014 & CMDs & + \\
\hline Hatchard 2012 & CMDs & + \\
\hline Karlson 2010 & CMDs & + \\
\hline Karlson 2014 & CMDs & + \\
\hline Martin 2015 & CMDs & + \\
\hline Nieuwenhuijsen 2004 & CMDs & + \\
\hline Post 2005 & CMDs & + \\
\hline Poulsen 2014 & CMDs & + \\
\hline Stahl 2014 & CMDs & + \\
\hline Tehiala 2013 & CMDs & + \\
\hline Van Beurden 2015 & CMDs & + \\
\hline \multicolumn{3}{|l|}{ Support from co-workers } \\
\hline Brouwer 2009 & MSDs + CMDs & + \\
\hline Brouwer 2010 & MSDs & + \\
\hline Brouwer 2011 & MSDs & + \\
\hline D'Amato 2010 & MSDs + CMDs & + \\
\hline Dunstan 2013 & MSDs & + \\
\hline Ekbladh 2004 & MSDs + CMDs & + \\
\hline
\end{tabular}


Table 3 (continued)

\begin{tabular}{|c|c|c|}
\hline Author & Condition & $\begin{array}{l}\text { Sustain- } \\
\text { able RTW } \\
\text { outcome }\end{array}$ \\
\hline Friesen 2001 & MSDs + CMDs & + \\
\hline Haugli 2011 & MSDs + CMDs & + \\
\hline Haveraaen 2016 & MSDs & + \\
\hline Jakobsen 2014 & MSDs & + \\
\hline Labriola 2006 & MSDs & + \\
\hline Laisne 2013 & MSDs & + \\
\hline Lysaght 2008 & MSDs + CMDs & + \\
\hline Selander 2015 & MSDs + CMDs & + \\
\hline Tjulin 2011 & MSDs + CMDs & + \\
\hline De Vries 2014 & CMDs & + \\
\hline Hatchard 2012 & CMDs & + \\
\hline Nielsen 2013 & CMDs & + \\
\hline Stahl 2014 & CMDs & + \\
\hline \multicolumn{3}{|l|}{ Negative outcomes } \\
\hline \multicolumn{3}{|l|}{ Support from leaders } \\
\hline Post 2005 & MSDs & - \\
\hline Ekberg 2015 & CMDs & - \\
\hline \multicolumn{3}{|l|}{ No effects } \\
\hline \multicolumn{3}{|l|}{ Support from leaders } \\
\hline Arnetz 2003 & MSDs & None \\
\hline Besen 2015 & MSDs & None \\
\hline Verbeek 2002 & MSDs & None \\
\hline Wahlin 2012 & MSDs & None \\
\hline Nielsen 2013 & CMDs & None \\
\hline Brouwer 2010 & CMDs & None \\
\hline Van Oostrom 2009 & CMDs & None \\
\hline Van Oostrom 2010 & CMDs & None \\
\hline Volker 2015 & CMDs & None \\
\hline \multicolumn{3}{|c|}{ Support from co-workers } \\
\hline Besen 2015 & MSDs & None \\
\hline Post 2005 & MSDs + CMDs & None \\
\hline Brouwer 2010 & CMDs & None \\
\hline Volker 2015 & CMDs & None \\
\hline \multicolumn{3}{|l|}{ Inconclusive outcomes } \\
\hline \multicolumn{3}{|l|}{ Job crafting } \\
\hline Bond 2001 & CMDs & $+/ ?$ \\
\hline Johansson 2006 & CMDs & $+/ ?$ \\
\hline Jakobsen 2014 & MSDs & $+/ ?$ \\
\hline Krause 2001 & MSDs & $+/ ?$ \\
\hline Marhold 2001 & MSDs & $+/ ?$ \\
\hline
\end{tabular}

Where sustainable RTW outcomes is represented as positive (+), negative (-), no effect (none), inconsistent $(+/-)$ and inconclusive $(+/$ ?)

return to work sustainably after an absence spell, thus suggesting the need for further research. Hence, the evidence presented is considered very low.

CMDs Two high-quality studies $(40,72)$ suggests the likelihood of women returning to work more sustainably than men, while two high-quality studies $(17,40)$ and one lowquality study (62) presented evidence of more sustainable RTW in men. Therefore, as with MSDs, there are inconsistencies in the evidence on sustainable RTW and gender, and the level of evidence is considered very low. 


\section{Education}

MSDs Five high-quality studies $(16,36,50,54,78)$ provided a moderate level of evidence that workers with a higher level of education are more likely to RTW sustainably than those with lower levels of education.

CMDs One low-quality study (22) indicated the positive impact of a low educational level on sustainable RTW. However, results from three high-quality studies $(16,54,78)$ provided contrary evidence suggesting that employees with a higher educational level are more likely to engage with the RTW process which impacts positively on a sustainable RTW. There is therefore very low level of evidence of an association between high educational level and sustainable RTW.

\section{Economic Status/Income}

MSDs There were no studies found to evaluate the effects of economic status/income on MSDs.

CMDs Results from one high-quality study (47) and one low-quality study (62) indicated that RTW was not a result of recovery from ill-health. Instead, it was influenced by employee's low income/economic status. However, the level of evidence provided is very low as a result of the limited number of studies reporting the effects of economic income/ status on RTW outcomes.

\section{Length of Absence}

MSDs One very high-quality study (68) and three highquality studies $(28,32,50)$ provided results indicating an effect of length of sickness absence, suggesting that to an extent, a short-term absence from work is likely to increase chances of a sustainable RTW. Therefore, there is a moderate level of evidence for this effect.

CMDs Findings from two high-quality studies $(25,32)$ showed that the chances of sustainable RTW is heightened for employees out on a short-term sick-leave for not more than a year compared to those out of work on a long-term basis. Therefore, there is a very low level of evidence to support the impact of length of absence on sustainable RTW outcomes.

\section{Job Contract/Security}

MSDs In two high-quality studies $(36,48)$, having a temporary and insecure job contract or working less than $40 \mathrm{~h} /$ week was associated with a sustainable RTW, providing a very low of evidence for this effect, with limited studies to draw definitive conclusions on lasting impacts of return.

CMDs Two high-quality studies $(36,47)$ investigating the effects of an employee's job contract/security on sustainable RTW showed that employees who are on a temporary or contract job and working less than $40 \mathrm{~h} /$ week are likely to RTW more sustainably regardless of ill-health condition compared to those with a permanent and secure working contract. This evidence was considered very low as a result of the few numbers of studies investigating this effect.

\section{Support from Leaders}

MSDs Forty studies evaluated the role of support from leaders. Fifteen very high-quality studies $(6,13,19,27,30,34$, $38,49,51,63,65,67,71,76,79)$, sixteen high-quality studies $(1,10,11,12,14,16,21,26,31,33,35,37,39,44$, $54,64)$ upgraded based on the GRADE criteria and 4 lowquality studies $(3,7,24,46)$ found sustainable RTW to be facilitated by support from leaders. Two very high-quality studies $(5,75)$ and two high-quality studies $(8,78)$ showed no effects of support from leaders on RTW outcomes. One high quality study (59) showed a negative effect of support from leaders on RTW outcomes. However, evidence synthesis provides a strong level of evidence suggesting that support from leaders does play a role in sustainable RTW outcomes in most instances.

CMDs Fifteen very high-quality studies (2, 4, 18, 27, 29, $30,34,41,51,53,60,63,66,71,72)$, eleven high-quality studies $(1,9,10,16,33,37,42,54,57,59,70)$ and two low-quality studies showed that workers perceived support from leaders as a positive influence on their ability to RTW sustainably. Three very high-quality studies $(56,73,74)$ and two high-quality studies $(11,77)$ indicated no effects on sustainable RTW. One low-quality study (22) indicated a negative effect on sustainable RTW due to support from leaders. There is therefore strong evidence suggesting the impact of support from leaders on sustainable RTW.

\section{Support from Co-workers}

MSDs Six very high-quality studies $(27,30,38,51,63,71)$, seven high-quality studies $(10,11,12,16,20,31,44)$ and two low-quality studies $(24,46)$ suggest that support from co-workers may have positive effects on sustainable RTW. However, one very high-quality study (59) and one highquality study (8) provided evidence of no such association. Therefore, there is strong evidence that support from coworkers plays a role in sustainable RTW outcomes. 
CMDs Eight very high-quality studies $(18,27,29,30,51$, $56,63,71)$, two high-quality studies $(10,16)$ and two lowquality study $(24,66)$ provided results regarding the good effects of support from co-workers on sustainable RTW. However, findings from three high-quality studies $(11,59$, 63) suggest that support from co-workers has no effects on sustainable RTW outcomes. Regardless, there is strong evidence suggesting that taking into account the effects of support from co-workers during the RTW process might be beneficial.

\section{Job Crafting}

MSDs Two very high-quality studies $(38,52)$ and one highquality study (43) provided evidence suggesting that sustainable RTW may be dependent on the employee's ability to optimize their jobs by applying job crafting practices. However, evidence was considered low as studies were too few to draw a definite conclusion.

CMDs Only two high-quality studies $(9,40)$ evaluating the effects of job crafting practices indicated positive effects on RTW outcome, however, providing a very low level of evidence with limited studies to conclude on its impact on a sustainable RTW.

\section{Evidence on Common Personal and Social Factors}

A summary of the evidence on common personal and social factors associated with sustainable RTW outcomes is presented in Table 3.

\section{Common Personal and Social Factors with Positive and Negative Sustainable RTW Outcomes}

There was a consistently positive effect of four personal and two social factors on sustainable RTW outcomes for people sick-listed with MSDs and CMDs. Personal factors included a positive attitude, high self-efficacy, employees of a younger age and a high educational level. Social factors included support from leaders and co-workers.

Even though support from leaders showed a consistently positive effect on sustainable RTW among people sick-listed with MSDs and CMDs in most studies, two studies reported the opposite relationship for both MSDs and CMDs $(59,22)$. In these studies, contrary to evidence found in a large number of studies, low supervisory support facilitated a sustainable RTW. However, external factors outside of the workplace had an impact on these outcomes.

\section{Common Personal and Social Factors with Inconsistent Sustainable RTW Outcomes}

Gender was the only personal factor across all included studies that produced inconsistent effects on sustainable RTW for people with MSDs and CMDs. Reports for MSDs RTW outcomes in one study indicated the possibility of women returning more sustainably than men (15). One study showed a sustainable RTW for both genders (48). While three studies recorded sustainable RTW for men only $(17,50,58)$. Reports for CMDs RTW outcomes also showed the same inconsistencies in findings. One study recorded more sustainable RTW among women (77) and two studies considered men more likely to RTW sustainably $(17,62)$. The contradiction in these results suggests the influence of another factor or factors on these RTW outcomes for both genders, hence the need for further research in this area.

\section{Common Personal and Social Factors with No Effect and Inconclusive Sustainable RTW Outcomes}

Personal factors showing inconclusive sustainable RTW for people with MSDs and CMDs included short-term sickness absence and temporary and insecure job contract. Across both MSDs and CMDs, the effect of job crafting was inconclusive because included studies were too few to infer firmly on their impact, thus warranting the need to investigate further on these effects.

We found a few studies where positive attitude $(11,18)$, a high self-efficacy (36), support from leaders $(5,8,75,78$, $56,11,73,74,77)$ and support from co-workers $(8,59,11$, 77) showed no effects on RTW outcomes. However, further investigation of these null outcomes showed the influence or absence of other factors which may have impeded expected RTW outcomes. For example, in three studies presence of a positive attitude towards work and the RTW process (25, 43) and a high self-efficacy (44) failed to impact on RTW outcomes due to the notable absence of social support in the workplace which was in other studies associated with expected outcomes.

\section{Discussion}

The main aim of this review was to assess the impact of personal and social factors on sustainable RTW after ill-health due to MSDs and CMDs and to identify commonalities of effects of these personal and social factors between both conditions. Across the literature on facilitators and barriers of RTW, personal and social factors may include a range of concepts not evaluated in this review. However, the evidence presented in this review is only limited to the factors identified in the included studies to influence sustainable RTW 
outcomes. Overall, sustainable RTW was evident across all RTW interventions or measures involving the personal and social factors evaluated. Effects of assessed personal and social factors were shared across both MSDs and CMDs, and the results were generally in the same direction. This review highlights that personal and social factors play vital roles in facilitating or impeding sustainable RTW after ill-health due to MSDs and CMDs, aligning with Alavi and Oxley's [6] findings. This may suggest that taking into account employees' personal and social factors when implementing RTW interventions or programmes will be more beneficial on RTW than modifying or adjusting their job role alone on RTW.

Findings from this review indicate that the effects of personal and social factors are likely to be correlated. Evidence suggests that sustainable RTW may be facilitated by employees having a positive attitude towards work and the RTW process and a high self-efficacy which are boosted by support from leaders and co-workers during the RTW process. This inference is from results from a few studies where the effects of attitude [24, 48] and self-efficacy [49] on sustainable RTW for people with CMDs was inhibited as a result of an absence of support at the workplace. According to Haveraaen et al. [50], high support from leaders and co-workers could improve the self-confidence and optimism of the returning worker, thus making them feel valued and worthy. This suggests that it is social support that may lead to better attitude and self-efficacy and therefore to better RTW outcomes. However, it is also possible that leaders and co-workers are more inclined to support employees who have a positive attitude towards work and the RTW process and a high confidence in their job competence which in turn impacts on sustainable RTW. The nature of the interaction between these factors is still unclear and should be studied in more detail in the future. Although support in the workplace showed a positive influence on sustainable RTW, however, across two studies that evaluated support from leaders [51, 52] among individuals with CMDs and MSDs respectively, the evidence did not align with these other findings. Instead, sustainable RTW was facilitated irrespective of the low level of support during the RTW process. These unusual findings can be explained that in these instances, workers returned to work despite being ill in order not to lose their jobs [51, 52].

Job crafting could be beneficial to employees with MSDs and CMDs returning to work after a period of absence. Findings suggested that its effect on sustainable RTW was associated with supportive interactions at the workplace [53-56]. Employees who felt supported by their line managers and co-workers and were given the opportunity to plan their jobs during the RTW process were more likely to have a high sense of control over their jobs. As a result, they were able to redesign their job tasks in a way that satisfied them, which in turn impacted sustainable
RTW outcomes. These conclusions support Wang et al.'s [57] and McClelland et al.'s [58] notion of support as an essential antecedent to the effectiveness of job-crafting. They assert that where leaders and co-workers work with employees in a supportive capacity, it is likely to increase the employee's motivation and thereby stimulate their job crafting abilities. However, evidence for the effects of job crafting on sustainable RTW is inconclusive as only a few numbers of studies have investigated this association, as such, it is unclear if other unknown factors have influenced these observed outcomes. Future research should, therefore, investigate the relationship between support from leaders and co-workers and employee's ability to craft their jobs and how that impacts sickness absence. Though included studies did not investigate the impact of collaborative job crafting (team-level job crafting), it might also be beneficial to probe further the effects of collaborative job crafting on RTW.

The effects of younger age, higher education, low economic status, a short-term length of absence, and a temporary and insecure job contract produced evidence suggesting its positive impact on sustainable RTW. Cancelliere et al.'s [18] findings also identified higher education levels and socioeconomic status as prognostic factors associated with positive RTW outcomes among people with MSDs and CMDs. This review thus verifies that association, suggesting the need to take into account employee's varied personal characteristics when implementing RTW measure for a more sustainable outcome.

Across the studies, younger aged workers were more likely to RTW sustainably than older employees, corresponding with Cornelius et al.'s [59] findings. Employees of the older workforce are considered more susceptible to ill-health, as such if they RTW, they had a higher probability of becoming ill again. Sustainable RTW outcomes were more prevalent among employees of a high educational level than employees of a lower educational level in all studies. The reviewed studies discovered that participants who were more willing to participate in RTW interventions were highly educated in all cases, had high quality jobs, stronger job resources, and higher expectations. According to Piha et al. [60], people with higher education levels are accorded more understanding and knowledge about healthrelated factors including health behaviours which helps them make healthier decisions in their everyday life and lifestyle which impacts positively on RTW outcomes. The likelihood of sustainable RTW was further increased among people with low income/economic status, temporary/contract jobs. Employees in these categories showed that it was more important to maintain their source of income and keep their job, hence the decision to RTW faster regardless of their health condition to avoid loss of employment as a result of extended absence. Positive effects on sustainable RTW were 
also identified among employees on a short-term absence from work [17, 61].

These conditions raise concerns about the risk of decisions to RTW while not fully recovered may pose to employees and the cost it may incur to employers. According to Whysall et al. [62], if RTW is not managed appropriately, this risk is likely to exacerbate existing medical conditions, impair quality of life, invite feelings of ineffectiveness at work and produce a cumulative psychological burden with consequences. As some personal factors like age or gender are not adjustable, employers have the responsibility to ensure they understand employees' conditions and provide adequate preventive measures to support them on RTW.

Results on the effects of gender were inconsistent. Previous studies have often identified men as the most likely to RTW sustainably [63-65]. Men are considered to be more willing to engage in the RTW process because they attribute more importance to their work [66]. However, in this review, we found some studies that reported that women were more likely to RTW more sustainably than men [67, 68], while other studies showed that men were more likely to RTW sustainably $[63-65,69]$. The discrepancies in these findings suggest the influence of additional factors on RTW outcomes. It is, therefore, unclear if the effects of gender vary based on factors such as the sector these individuals work in or the organizational culture in the workplace. Moreover, it is possible that factors that influence RTW outcomes for men and women vary, hence the need to conduct further research on these effects to understand precisely the factors that affect RTW outcomes for both men and women.

This review revealed common personal and social factors associated with a positive, sustainable RTW outcome for people sick-listed with both MSDs and CMDs. They included a positive attitude, high self-efficacy, younger age, higher education, and support from leaders and co-workers. Rather than tackling MSDs and CMDs separately, recognizing these common factors will be a beneficial step for employers in implementing a holistic RTW approach/intervention for both conditions. According to Naylor et al. [27], if the integration of mental and physical health does not form a significant component of programmes, it would be a significant missed opportunity.

\section{Strengths, Limitation and Gaps in Evidence}

The review process had the aim of being thorough, transparent and reproducible, and the critical appraisal method allowed for the inclusion of high-quality papers. A wide range of study designs was included with the intention of avoiding an overlook of evidence that is often considered too weak for inclusion. However, it is possible that the selection approach adopted in this process could have increased the risk of selection bias which may have resulted in the exclusion of potentially relevant studies. It is also possible that some studies that would have been relevant to this review have not been identified because of them being unpublished.

One of the strengths of this review lies in the methodological build-up. Reporting the effects of a variety of personal and social factors and identifying the commonalities between conditions may have introduced a degree of complexity to the analytical process. Harvest plots were developed for ease of synthesis and visual display of evidence to support competing hypotheses about the impact of evaluated factors on sustainable return to work for both conditions separately. This graphical method of synthesizing findings adapted from Thomas et al. [44] seemed very useful to synthesize evidence across multiple sources.

The review revealed several gaps in the currently available evidence. Most notable is a lack of sufficient literature evaluating the effects of job crafting, economic status, length of absence and job contract/security on sustainable return to work, making it challenging to draw confident conclusions. Hence, it would be useful to conduct further research in these areas to aid clear conclusions regarding its effects. Additionally, this review identified inconsistent results surrounding the impact of gender on sustainable RTW, suggesting the influence of other factors.

\section{Conclusion}

Alavi and Oxley [6] assert that when research concentrates more on learning about factors associated with sustainable RTW, significant gains in RTW programs will be achieved. This review addresses this call by contributing evidence towards understanding the role of various factors that facilitate a sustainable RTW for workers sick-listed with MSDs and CMDs.

Personal and social factors play a role in facilitating sustainable RTW after ill-health due to MSDs and CMDs. However, sustainable RTW does not appear to be the result of a single factor. Instead, sustainable RTW seems to be influenced by an interplay of multiple factors. Here the most consistent evidence for sustainable RTW was found for support from leaders and co-workers, positive attitude, high self-efficacy, younger age and higher education levels.

The results of this review indicate that existing RTW programmes need to encourage supportive interactions between leaders and co-workers and returning workers during the RTW process [70], especially as this could have a direct effect on sustainable RTW, as well as an indirect effect through enhanced returners' attitudes toward work and selfefficacy. Also, it suggests a role for the state in encouraging employers to implement RTW strategies that factor in management (and other) support and to work on developing 
positive attitude and self-efficacy among returning workers. Although RTW takes place within a complex system involving employing organizations and the healthcare system, given the consistent evidence of the role line managers play in sustainable RTW, we recommend that policymakers consider ways to provide guidance for employers. Guidance could: outline the supportive role of line managers and other key workplace professionals (e.g., human resources professionals, occupational health providers) during the return to work process; train these key workplace professionals on the return to work process and how to effectively manage and support returning workers; and outline ways to facilitate line managers in providing necessary support. Promoting a culture of support at the workplace is essential, a culture that makes returning workers feel valued, worthy and not necessarily blamed for absence, as the former would improve work attitudes and ease the transition back to work.

Author Contributions AE was the lead author and contributed to the study design, screening process, eligibility process, data extraction, methodological quality evaluation, data analysis and write up (as a reviewer). $\mathrm{KD}$ and $\mathrm{CE}$ were the study supervisors and contributed to the screening process, the eligibility process, data extraction, revised the paper critically and contributed to it intellectually. All the authors have read and approved the final version of the manuscript.

Funding The research is funded by the University of East Anglia. The funding source had no involvement in decisions regarding study design; collection, analysis, or interpretation of the data; writing of the article; and in decision to submit the article for publication.

\section{Compliance with Ethical Standards}

Conflict of interest All authors declare that they have no conflict of interest.

Open Access This article is distributed under the terms of the Creative Commons Attribution 4.0 International License (http://creativeco mmons.org/licenses/by/4.0/), which permits unrestricted use, distribution, and reproduction in any medium, provided you give appropriate credit to the original author(s) and the source, provide a link to the Creative Commons license, and indicate if changes were made.

\section{References}

1. Hill J. Safety and health practitioner. 2015. https://www.shponline. co.uk/the-main-causes-of-workplace-ill-health/. Accessed 04 Dec 2017

2. Health and Safety Executive (HSE). Health and safety executive. 2015. http://www.hse.gov.uk/statistics/overall/hssh1415.pdf. Accessed 18 Dec 2018

3. Henderson M, Glozier N, Elliot KH. Long term sickness absence. BMJ. 2005;330(7495):802-803.

4. Robinson SS. Reducing repetitive motion injuries with preventive ergonomic strategies. Public Health Rep. 1994;109(2):182-183.
5. International Stress Management Association (ISMA). Promoting stress prevention and well-being: facts about stress. 2012. http:// isma.org.uk/about-stress/facts-about-stress/. Accessed 30 Nov 2016

6. Alavi H, Oxley J. Institute for safety, compensation and recovery research. 2013. https://www.iscrr.com.au/_data/assets/ pdf_file/0009/297756/return-to-work-and-occupational-illnessand-injury-rehabilitation.pdf. Accessed 11 Dec 2016

7. Waddel G, Burton AK. Is work good for your health and wellbeing? 2006. https://cardinal-management.co.uk/wp-content/ uploads/2016/04/Burton-Waddell-is-work-good-for-you.pdf. Accessed 04 Dec 2017

8. Cullen KL, Irvin E, Collie A, Clay F, Gensby U, Jennings PA, et al. Effectiveness of workplace interventions in return-to-work for musculoskeletal, pain-related and mental health conditions: an update of the evidence and messages for practitioners. J Occup Rehabil. 2018;28(1):1-15.

9. Mikkelsen MB, Rosholm M. Systematic review and meta-analysis of interventions aimed at enhancing return to work for sick-listed workers with common mental disorders, stress-related disorders, somatoform disorders and personality disorders. Occup Environ Med. 2018;75(9):675-686.

10. Lammerts L, Schaafsma FG, Eikelenboom M, Vermeulen SJ, Mechelen WV, Anema JR, et al. Longitudinal associations between biopsychosocial factors and sustainable return to work of sick-listed workers with a depressive or anxiety disorder. J Occup Rehabil. 2016;26(1):70-79.

11. Nigatu YT, Liu Y, Uppal M, McKinney S, Rao S, Gillis K, et al. Interventions for enhancing return to work in individuals with a common mental illness: systematic review and meta-analysis of randomized controlled trials. Psychol Med. 2016;46(16):3263-3274.

12. Dewa CS, Trojanowski L, Bonato S. Employer best practice guidelines for the return to work of workers on mental disorderrelated disability leave: a systematic review. Can J Psychiatry. 2016;61(3):176-185.

13. van Vilsteren M, van Oostrom SH, de Vet HC, Franche RL, Boot CR, Anema JR. Workplace interventions to prevent work disability in workers on sick leave. Cochrane Database Syst Rev. 2015. https://doi.org/10.1002/14651858.CD006955.pub3

14. Arends I, Bruinvels DJ, Rebergen DS, Nieuwenhuijsen K, Builtman U, Verbeek JH. Cochrane library. 2012. Available from: http://onlinelibrary.wiley.com/doi/10.1002/14651858.CD006389. pub2/epdf.

15. Carroll CS, Rick J, Pilgrim H, Cameron J, Hillage J. Workplace involvement improves return to work rates among employees with back pain on long-term sick leave: a systematic review of the effectiveness and cost-effectiveness of interventions. Disabil Rehabil. 2010;32(8):607-621.

16. Franche RL, Cullen K, Clarke J, Irvin, Sinclair S, Frank J, et al. Workplace-based return-to-work interventions: a systematic review of the quantitative literature. J Occup Rehabil. 2004;15(4):607-631.

17. Krause N, Dasinger LK, Neuhauser F. Modified work and return to work: a review of the literature. J Occup Rehabil. 1998;8(2):113-139.

18. Cancelliere C, Donovan J, Stochkendahl MJ, Biscardi M, Ammendolia C, Myburgh C, et al. Factors affecting return to work after injury or illness: best evidence synthesis of systematic reviews. Chiropractic Manual Ther. 2016;24(32):1-23.

19. Franche RL, Severin CN, Hogg-Johnson S, Côté P, Vidmar M, Lee $\mathrm{H}$. The impact of early workplace-based return-to-work strategies on work absence duration: a 6-month longitudinal study following an occupational musculoskeletal injury. J Occup Environ Med. 2007;49(9):960-974. 
20. Gallagher RM, Rauh V, Haug LD, Milhous R, Callas PW, Langelier R, et al. Determinants of return-to-work among low back-pain patients. PAIN. 1989;39(1):55-67.

21. Kelly A. A supportive, ability-focused return-to-work program can provide substantial benefits for employees and employers alike. Plans Trusts. 2012;30(6):8-12.

22. Hoefsmit N, Houkes I, Boumans N, Noben C, Winkens B, Nijhuis FJN. The effectiveness of an intervention to enhance cooperation between sick-listed employees and their supervisors (COSS). J Occup Rehabil. 2016;26(2):229-360.

23. Tjulin $\AA$, Maceachen E, Stiwne EE, Ekberg K. The social interaction of return to work explored from co-workers experiences. Disabil Rehabil. 2011;33(21-22):1979-89.

24. Brouwer R. Groothoff JW. A prospective study of return to work across health conditions: perceived work attitude, self-efficacy and perceived social support. J Occup Rehabil. 2010;20(1):104-112.

25. Durand MJ, Corbiere M, Coutu MF, Reinharz D, Albert V. A review of best work-absence management and return-to-work practices for workers with musculoskeletal or common mental disorders. Work. 2014;48(4):579-589.

26. Kendall N, Burton K, Lunt J, Mellor N, Daniels K. Developing an intervention toolbox for the common health problems in the workplace. London; 2016.

27. Naylor C, Das P, Ross S, Honeyman M, Thompson J, Gilburt H. Bringing together physical and mental health. A new frontier for integrated care. 2016. https://www.kingsfund.org.uk/sites/default/ files/field/field_publication_file/Bringing-together-Kings-FundMarch-2016_1.pdf. Accessed 03 Aug 2018

28. Heuvel VD. OSHWiki. 2017. https://oshwiki.eu/index.php?title =Psychosocial_risk_factors_for_musculoskeletal_disorders_ (MSDs)\&oldid=246772. Accessed 03 Aug 2018

29. Lloys C, Waghorn G, McHugh C. Musculoskeletal disorders and comorbid depression: implications for practice. Aust Occup Ther J. 2008;55(1):23-29.

30. Demou E, Smith S, Bhaskar A, Mackay D, Brown J, Hunt K, et al. Evaluating sickness absence duration by musculoskeletal and mental health issues: a retrospective cohort study of Scottish healthcare workers. BMJ Open. 2018;8(1):e018085.

31. Krause N, Frank JW, Dasinger LK, Sullivan TJ, Sinclair SJ. Determinants of duration of disability and return-to-work after workrelated injury and illness: challenges for future research. Am J Ind Med. 2001;40(4):464-484.

32. Jensen C, Jensen OK, Nielsen CV. Sustainability of return to work in sick-listed employees with low-back pain. Two-year follow-up in a randomized clinical trial comparing multidisciplinary and brief intervention. BMC Musculoskelet Disord. 2012;13(1):156-164.

33. Berg JM, Dutton JE, Wrzesniewski A. What is job crafting and why does it matter? Ann Arbor, MI: University of Michigan Ross School of Business. 2008. http://positiveorgs.bus.umich.edu/wpcontent/uploads/What-is-Job-Crafting-and-Why-Does-it-Matte r1.pdf. Accessed 02 Nov 2016

34. Petrou P, Demerouti E, Schaufeli WB. Job crafting in changing organizations: antecedents and implications for exhaustion and performance. J Occup Health Psychol. 2015;20(4):470-480.

35. Wrzesniewski A, Dutton JE. Crafting a job: revisioning employees as active crafters of their work. Acad Manag Rev. 2001;26(2):179-201.

36. Shamseer L, Moher D, Clarke M, Ghersi D, Liberati A, Petticrew $\mathrm{M}$, et al. Preferred reporting items for systematic review and metaanalysis protocols (PRISMA-P) 2015: elaboration and explanation. BMJ. 2015;350:g7647.

37. Centre for Review and Dissemination (CRD). Systematic reviews: CRD's guidance for understanding reviews in health. 2006. https ://www.york.ac.uk/media/crd/Systematic_Reviews.pdf. Accessed 18 Nov 2016
38. Grimani A, Bergström G, Casallas MI, Aboagye E, Jensen I, Lohela-Karlsson M. Economic evaluation of occupational safety and health interventions from the employer perspective: A systematic review. J Occup Environ Med. 2018;60(2):147-166.

39. Stretch D, Sofaer N. How to write a systematic review of reasons. J Med Ethics. 2012;38(2):121-126.

40. Snape D, Meads C, Bagnall AM, Tregaskis O, Mansfield L, ResearchGate. 2016. https://www.researchgate.net/publicatio n/312119535_What_Works_Wellbeing_A_guide_to_our_evide nce_review_methods. Accessed 14 Dec 2016

41. Higgins JPT, Green S. Cochrane handbook for systematic reviews of interventions, Vol. 5. 5102011th eds. Higgins JPT, Green S, editors. Chichester: Wiley-Blackwell: The Cochrane Collaboration; 2011.

42. Lewin S, Glenton C, Munthe-Kaas H, Carlsen B, Colvin CJ, Gülmezoglu $\mathrm{M}$, et al. Using qualitative evidence in decision making for health and social interventions: an approach to assess confidence in findings from qualitative evidence syntheses (GRADECERQual). PLOS. 2015;12(10):1-18.

43. Khan KS, Kunz R, Kleijnen J, Antes G. Systematic review to support evidence-based medicine. How to review and apply findings of health care research. 2nd ed. London: The Royal Society of Medicine Press Ltd; 2011.

44. Thomas S, Fayter D, Misso K, Ogilvie D, Petticrew M, Sowden A, et al. Population tobacco control interventions and their effects on social inequalities in smoking. Syst Rev BMJ J. 2008;17(4):230-237.

45. Barnett I, Van Sluijs EM, Ogilvie D. Physical activity and transitioning to retirement. A systematic Review. Am J Prev Med. 2012;43(3):329-336.

46. World Health Organization. International classification of functioning, disability and health (ICF). 2001. http://www.who.int/ classifications/icf/en/. Accessed 25 July 2018

47. Watson D, Tregaskis O, Gedikli C, Vaughn O, Semkina A. Wellbeing through learning: a systematic review of learning interventions in the workplace and their impact on well-being. Eur J Work Organ Psychol. 2018; 27(2):247-268.

48. De Vries G, Hees HL, Koeter MWJ, Lagerveld SE, Schene AH. Perceived impeding factors for return-to-work after long-term sickness absence due to major depressive disorder: a concept mapping approach. PLoS ONE. 2014;9(1):1-10.

49. Huijs JJ, Koppes LL, Taris TW, Blonk RW. Differences in predictors of return to work among long-term sick-listed employees with different self-reported reasons for sick leave. J Occup Rehabil. 2012;22(3):301-311.

50. Haveraaen LA, Skarpaas LS, Berg JE, Aas RW. Do psychological job demands, decision control and social support predict return to work three months after a return-to-work (RTW) programme? The rapid-RTW cohort study; 2016. https://oda-hioa.archive.knowl edgearc.net/bitstream/handle/10642/3233/1210967post.pdf?seque nce $=1$. Accessed 18 May 2017

51. Ekberg KW, Wahlin C, Persson J, Bernfort L, Oberg B. Early and late return to work after sick leave: predictors in a cohort of sick-listed individuals with common mental disorders. J Occup Rehabil. 2015;25(3):627-637.

52. Post M, Krol B, Groothoff JW. Work-related determinants of return to work of employees on long-term sickness absence. Disabil Rehabil. 2005;27(9):481-488.

53. Bond FW, Bunce D. Job control mediates change in a work reorganization intervention for stress reduction. J Occup Health Psychol. 2001;6(4):290-302.

54. Krause N, Dasinger LK, Deegan LJ, Rudolph L, Brand RJ. Psychosocial job factors and return-to-work after compensated low back injury: a disability phase-specific analysis. Am J Ind Med. 2001;40(4):374-392. 
55. Johansson G, Lundberg O, Lundberg I. Return to work and adjustment latitude among employees on long-term sickness absence. J Occup Rehabil. 2006;16(2):181-191.

56. Jakobsen K, Lillefjell M. Factors promoting a successful return to work: from an employer and employee perspective. Scand J Occup Ther. 2014;21(1):48-57.

57. Wang HJ, Demerouti E, Le Blanc P. Transformational leadership, adaptability and job crafting; the moderating role of organizational identification. J Vocat Behav. 2017;100:185-195.

58. McClelland GP, Leach DJ, Clegg CW, McGowan I. Collaborative crafting in call centre teams. J Occup Organ Psychol. 2014;87(3):464-486.

59. Cornelius LR, Van Der Klink JJL, Groothoff JW, Brouwer S. Prognostic Factors of long term disability due to mental disorders: a systematic review. J Occup Rehabil. 2011;21(21):259-274.

60. Piha K, Laaksonen M, Martikainen P, Rahkonen O, Lahelma E. Interrelationships between education, occupational class, income and sickness absence. Eur J Pub Health. 2009;20(3):276-280.

61. Conroy M. Supporting an injured worker return to work. Workplace safety initiative; 2017. http://www.re-integrate.eu/resources/ supporting-an-injured-worker-return-to-work.pdf. Accessed 06 Jan 2017

62. Whysall Z, Bowden J, Hewitt M. Sickness presenteeism: measurement and management challenges. Ergonomics. 2017;61(3):341-354.

63. De Rijk A, Janssen N, Alexanderson K, Nijhuis F. Gender differences in return to work patterns among sickness absentees and their associations with health: a prospective cohort study in The Netherlands. Int J Rehabil Res. 2008;31(4):327-336.

64. Lydell M, Grahn B, Mansson J, Baigi A, Marklund B. Predictive factors of sustained return to work for persons with musculoskeletal disorders who participated in rehabilitation. Work. 2009;33(3):317-328.
65. Opsahl J, Eriksen HR, Tveito TH. Do expectancies of return to work and Job satisfaction predict actual return to work in workers with long lasting LBP? BMC Musculoskelet Disord. 2016;17(1):481-491.

66. Laisné F, Lecomte C, Corbière M. Biopsychosocial determinants of work outcomes of workers with occupational injuries receiving compensation: a prospective study. Work. 2013;44(2):117-132.

67. Crook J, Moldofsky $\mathrm{H}$. The probability of recovery and return to work from work disability as a function of time. Qual Life Res. 1994;31(1):S97-S109.

68. Volker D, Zijlstra-Vlasveld MC, Brouwers EPM, Van Lomwel AGC, Van Der Feltz-Cornelis CM. Return-to-work self-efficacy and actual return to work among long-term sick-listed employees. J Occup Rehabil. 2015;25(2):423-431.

69. Roelen CAM, Norder G, Koopmans PC, Van Rhenen W, Van Der Klink JJL, Bültmann U. Employees sick-listed with mental disorders: who returns to work and when? J Occup Rehabil. 2012;22(3):409-417.

70. Health and safety executive. Managing sickness absence and return to work; 2004. http://www.hse.gov.uk/pUbns/priced/hsg24 9.pdf. Accessed 16 Nov 2016

71. Moher D, Liberati A, Tetzlaff J, Altman DG, The PRISMA Group. Preferred reporting items for systematic reviews and metaanalyses: the PRISMA statement. PLoS Med. 2009. https://doi. org/10.1371/journal.pmed1000097

Publisher's Note Springer Nature remains neutral with regard to jurisdictional claims in published maps and institutional affiliations. 